\title{
The Market Effects of Patent Litigation
}

\author{
Matthew D. Henry \\ Department of Economics, Cleveland State University, Cleveland, USA \\ Email: m.d.henry42@csuohio.edu
}

Received September 30, 2012; revised October 29, 2012; accepted November 7, 2012

\begin{abstract}
This study measures the value of patents to firms and identifies factors that contribute to that value by observing the abnormal change in firms' stock market values following court decisions. Firms lose $0.85 \%$ (about $\$ 19$ million) of their value following a decision that one of their patents is "Invalid", but only gain about $0.7 \%$ following a "Valid \& Infringed" decision. The factors that that affect the expectations of investors as to the enforceability of patent rights are at least as important in determining the contribution of the patent to the firm's market value as are characteristics of the patent. Most prominently, this confirms the substantial impact that the creation of the Court of Appeals for the Federal Circuit (CAFC) had on the value of patents. After the creation of the CAFC, "Invalid" decisions resulted in a $0.7 \%$ (about $\$ 15.5$ million) greater loss of firm value. Clearly, patents are more valuable because of this change in the legal landscape.
\end{abstract}

Keywords: Patents; Litigation; Valuation

\section{Introduction}

Accurate patent valuation has been a troubling question for researchers and intellectual property managers for some time. Unlike a tangible asset with well defined property rights, the patent conveys to its owner a "negative right" of exclusion of others ${ }^{1}$. This right may be valuable to the firm for numerous reasons, including protection of a market for the firm's product, generating licensing revenue, or as a defense from suits from competitors. It is impossible to quantify the value to the firm of these various uses of a patent individually. Assuming that the stock market is efficient, the value of the patent as a whole should be reflected in the total market value of the firm. Changes in the firm's market value can reveal important information about the company's intellectual property portfolio.

I develop a model of how a firm's market value should react contingent on a court ruling on one of the firm's patents. I then test this model using a subset of data originally gathered for and published in [2]. The subset has rulings on 544 patents that were published in the United States Patent Quarterly between 1962-2002. I find that the average firm loses about $0.85 \%$ of its market value following a decision that one of their patents was "Invalid", and firms gain about $0.7 \%$ in market value following a "Valid \& Infringed" decision. I also conduct a cross-sectional analysis of the changes to the market values, in which I consider two types of factors that can

\footnotetext{
${ }^{1}$ See [1], page 27 .
}

determine the value of a patent: the expectations of enforceability of the patent and the characteristics of the patent. I find that the expectations aspect is at least as important in determining value as the characteristics of the patent. Importantly, the creation of the Court of Appeals for the Federal Circuit (CAFC), which is generally thought to be decidedly pro-patent, substantially increased the value of patents to firms ${ }^{2}$. For instance, I find that while a firm, on average, loses $0.85 \%$ (about $\$ 19$ million) of its market value following a court decision that a patent is "Invalid", the average decline in firm value was $0.7 \%$ greater after the establishment of the CAFC. Thus, patents were, on average, about $\$ 15.5$ million more valuable because of the creation of the CAFC. Additionally, there is some evidence that a measure of a court's "friendliness" toward patent holders may also affect the change in market value of the firm.

Previous researchers have only focused on the characteristics of the patent. [3] study litigated patents, which they argue are more valuable. They find litigated patents are typically younger, owned domestically, issued to

\footnotetext{
${ }^{2}$ The CAFC was created by legislation in 1982 (and started hearing cases in 1983) to unify intellectual property law and, ostensibly, to end forum shopping in patent cases. The CAFC hears cases appealed from any federal district court in the nation. Prior to its creation, appeals would be heard by the circuit court of the circuit in which the district court was located and the outcome of the case could have been contingent on where it was litigated. Since its creation, the CAFC has garnered a reputation as being "pro-patentee". The evidence supports this conclusion as to the question of validity, but not for the infringement question. For a more thorough description of the court and the changes in outcomes over time, see [2].
} 
individuals or small companies, cite more prior art and are cited more by others, have longer prosecution times, more claims, and are concentrated in certain industries, such as the mechanical, computer and medical device industries $^{3}$. [5] compares the characteristics of patents that are maintained longer ${ }^{4}$ to conclude that more claims, more citations made and received, longer prosecution times, having related patent applications (continuations and divisions), a greater number of inventors, foreign ownership, and being in the computers classification all contribute to more valuable patents. [6] studies the relationship between the value of intangible assets of firms (stock market value minus tangible assets) and research and development expenditures, patents, and patent citations. In particular, the authors find that firms whose patents are more frequently cited by subsequent patents have a higher market valuation.

Focusing only on the characteristics of the patent ignores an important aspect of property rights-for property rights to be valuable, the rights must be enforceable. No one would invest in property if others could infringe upon it without recourse. Likewise, patents would be worthless and inventors wouldn't disclose new technology if their intellectual property rights were not enforceable ${ }^{5}$. Therefore, characteristics of the legal system are also important in determining the ultimate value that a firm may derive from a patent.

Many papers use event studies to study litigation, usually focusing on the filing of the suit ${ }^{6}$. However, only two previous papers use event studies to examine the

${ }_{3}^{3}[4]$ Also find that the number of claims in a patent and the number of citations of the patent are important determinants of whether a patent will eventually be litigated.

${ }^{4}$ To maintain a patent, fees must be paid four, eight, and twelve years after they are granted. If the fees are not paid, the patent is deemed expired. Patent holders will only keep the patent current if the value of the patent is greater than the fees. Therefore, more valuable patents should be maintained longer.

${ }^{5}$ The lack of an enforceable patent system wouldn't completely destroy incentives to innovate, it would certainly diminish the incentive. Additionally, this would slow down the diffusion of ideas, which would slow technological progress in general.

${ }^{6}[7]$ give an in-depth study of five suits in which both the plaintiff and defendant were corporations and find significant leakages of the value for the two firms involved. [8], as part of a more comprehensive study, find that upon filing of a patent infringement suit, the 31 defendant firms lost an average of $1.2 \%$ of their market value, while plaintiff firms showed little change in value. [9] expand on this earlier work by considering more lawsuits. The authors find that upon filing the lawsuit, the defendant firm (with 33 observations) lost an average of $1.5 \%$ of firm value and the 51 plaintiff firms lost an average of $0.31 \%$ of their value. [10] finds that on the announcement of a patent suit, the plaintiff's value drops a small amount and defendants lose nearly $3 \%$ of their value. [11] and [12] survey event studies that have been conducted on various aspects of corporate litigation. They find only one study that showed that the plaintiffs benefit (in terms of increasing firm value) at the time a lawsuit was filed, and that study ([13]) was limited to private antitrust suits. Although I don't consider the filing date in this paper, I assume, based on the prior work, that the plaintiffs have not experienced any change in firm value on the filing date. results of court decisions on patents ${ }^{7}$. [15] studies the effect of 475 court decisions (in 295 adjudications) published in the United States Patent Quarterly (USPQ) between 1977 and 1997. The goal of this paper is the same as the present study, but the methods used differ significantly, and the results are therefore not directly comparable. Rather than separating the different types of decisions prior to presenting the results, Marco finds the abnormal returns (using an event study) for all the decisions and then regresses the returns on dummy variables for the decision rendered ("Valid", "Not Valid", "Infringed", and "Not Infringed") ${ }^{8}$. Doing so assumes independence of the types of decisions, and allows for intermediate decisions (for instance, in a bifurcated trial) to count the same as final decisions. Clearly, this is problematic and I focus only on final adjudications. Additionally, he uses a bootstrap procedure allowing the return for each observation selected to be defined by a randomly drawn event window. Thus, I can not compare my results from each event window directly to his.

Another refinement in his paper is the use of the Expectation-Maximization Algorithm to separate the effects of decisions on multiple patents in the same suit. As he acknowledges, the use of this technique assumes independence of the decisions. Because this assumption is problematic, I choose not to follow the same technique, but attempt to control for other decisions in the same case in my cross-sectional analysis. Finally, he compares the results of various sub-samples to analyze the effect of the creation of the CAFC, whether the decision was by a district court or appellate court, and whether the plaintiff in the case was the patentee or the alleged infringer. Although he does not find a statistically significant difference in district and appellate decisions, lumping both types of decisions together in presenting his main results is problematic. The expectations of investors should be far different when facing an appellate decision rather than the initial district decision, especially given that one judge has already ruled on the case. However, Marco doesn't have any way to control for the underlying district court decision when the appellate decision is rendered. Thus, he values a reversal from "Invalid" to "Valid" the same way he values an affirmation of a "Valid" decision, despite the fact that investors should react to the former situation in a much more dramatic way. Because of this problem, I use only decisions by district courts. Finally, this technique of comparing two sub-samples ignores other conflating factors that could

\footnotetext{
${ }^{7}[14]$ uses an event study to find the returns to patent issuance.

${ }^{8}$ The results for each type of decision are also reported independently, but each observation could fall into multiple categories, for instance, both valid and infringed. Conversely, I treat each decision separately in reporting my results, and therefore, each observation only appears once.
} 
be influencing the results. Therefore, I choose to use a cross-sectional regression analysis to analyze the effect of the creation of the CAFC and control for whether the patentee was the plaintiff.

[16] uses abnormal returns to determine whether court decisions were "correct". Since investors can form some a priori judgment of the validity of a patent, the more shocking a judge's decision in the case is, the more the value of the firm drops. Therefore, he uses the abnormal return as a independent variable in a maximum likelihood estimation to calculate the change in beliefs about the validity of a patent. This estimation also allows him to conclude how often judges get the decision "wrong". He finds that invalid patents are rarely held valid, but valid patents are often declared invalid. In addition to the other estimates, Marco presents the results of the event study (which was an intermediate step for him). Using the same data as in his other paper, he finds that valid decisions (with 55 observations) result in a 1.52\% increase in firm value over an 11-day event window (five days prior to the decision until five days after). The result for a two day window (day of the event until the day after) for valid decisions was insignificant. The return on invalid decisions (45 observations) was $-0.64 \%$ for the two day event window and $-0.82 \%$ for the 11 -day event window (though the later figure is less statistically significant). These figures will be useful to compare to my findings later.

In addition to the differences noted above, the current study is distinct from Marco's in several fundamental ways. First, I have a larger data set to consider. I have almost twice as many district court decisions. Additionally, the decisions I consider are more balanced on the creation of the CAFC, allowing for a more precise study of the effect of the new court. Second, I more precisely define the decision that is being render and consider the various decisions separately to avoid conflating results. [15] uses intermediate decisions and separates the validity and the infringement inquiries in his analysis. [16] excludes infringement decisions altogether because of the additional noise that they introduce into the system. An infringement decision must also consider the actions of the alleged infringer, rather than just the patent. However, excluding infringement decisions discounts the fact that a court's interpretation of the scope of a patent may significantly alter its value and the difference in returns possible between a "Valid \& Infringed" decision and a "Valid", but "Not Infringed" decision. Third, I consider both expectation factors and characteristics of the patents to explain the observed changes in market values.

In addition to being the most comprehensive study of the market effects of patent litigation to date, my finding that the creation of the CAFC increases patent value also sheds light on the debate as to why there was a surge in patenting activity in the early 1980's. [17] argue that an increase in the productivity of R \& D was responsible for this surge; [18] concludes that the CAFC was part of the cause. My findings tend to confirm the later opinion. The marginal cost of patenting remained relatively the same, while the marginal benefits (in terms of increasing firm value) were apparently increasing. Therefore, there were more patent applications filed.

The following section presents the theory as to what is measured by the event study method. The third section describes the data collected and used. The fourth, fifth and sixth sections describe the empirical method and present the results of the event study and the cross-sectional analysis. The final section makes some concluding remarks and some suggests for future re-search.

\section{Modeling the Market Reaction}

The first step in litigation usually occurs when the patent holder files the suit. Previous work has shown that there is no significant change in the plaintiff's market value based on this filing 9 . The decision to file suit may also be made by the alleged infringer through the use of declaratory judgment action asking the court to find a patent invalid or not infringed. To entertain a declaratory judgment action, the court must find that an actual controversy exists between the parties. For instance, the patent holder may have sent a "cease and desist" letter or threatened judicial action prior to the filing of the suit. Because there may be differences in the selection of patents for litigation based on who files the suit, I control for this variable in the cross-sectional analysis ${ }^{10}$.

I ignore the decision of whether to appeal and assume that the district court decision terminates the litigation. This assumption is inconsequential in considering the market reaction to the district court's decision because investors probably do not know whether the decision will be appealed during the event window. I also ignore the costs of the litigation because the costs will be paid regardless of the outcome of the suit (and should therefore, already be incorporated in the market value of the firm).

There are three possible decisions the court can render: "Valid \& Infringed", "Invlaid" or "Not Infringed" $"$. Let

\footnotetext{
${ }^{9}$ See, e.g., $[8,10,19]$.

${ }^{10}$ The decision to file suit can also be used strategically. For instance, particularly in the pre-CAFC era, the ultimate outcome of the suit may have been contingent on the forum, making naming the forum an important strategic decision.

${ }^{11}$ While the validity and infringement issues are separate inquiries by the court, I assume that the ultimate decision of the court is one of these three possibilities. The court does not necessarily need to rule on both issues, it can rule in favor of the alleged infringer on either question and not address the other. Therefore, there is no need to separate the decisions into "Invalid \& Not Infringed" and "Valid, but Not Infringed". An invalid patent could never be infringed. If it is not infringed, there is no reason to address the validity, and therefore the patent-holder retains the rights of the patent.
} 
$V$ be the payout to the firm if the patent is declared to be "Valid \& Infringed". This includes retaining the value of the patent, damages that are won in this trial, and any increase in expected damages from future suits. The payoff to the firm following a "Not Infringed" decision will then be $\alpha V$, where $\alpha$ is between 0 and 1 . The simplest explanation for this reduction to $V$ is that it excludes the damages that would have been awarded if the patent had been found to be infringed. However, it may also be the case that the court has narrowed the scope of the patent in declaring it to be not infringed, which would necessarily reduce the value of the patent to the firm. The payout to the firm following an "Invalid" decision is 0 because the value of the patent is completely lost.

Let $\beta$ be the a priori probability that the decision of the court will be "Invalid" and $\gamma$ be the a priori probability of a "Not Infringed" decision. Both variables are between 0 and 1 . The probability of a "Valid \& Infringed" decision then becomes $1-\beta-\gamma$.

With the parameters defined, setting up the expectations equation is straight forward.

$$
E(\pi)=(1-\beta-\gamma) V+\gamma(\alpha V)+\beta 0
$$

From Equation (1), we can derive the change in expectations that will occur whenever any court decision is rendered. For instance, when a decision that a patent is "Invalid" is rendered, the patent is worth 0 . Therefore, for the patent holder, the change in the expected firm value $(\pi)$ from the suit due to the decision can be expressed as ${ }^{12}$ :

$$
\Delta E(\pi \mid I N)=0-E(\pi)=-V[(1-\beta-\gamma)+\alpha \gamma]
$$

Similar equations can be found for the change in expectations conditional on the two other types of decisions:

$$
\begin{gathered}
\Delta E(\pi \mid V I)=V[\beta+\gamma(1-\alpha)] \\
\Delta E(\pi \mid N I)=V[\alpha(1-\gamma)-(1-\beta-\gamma)]
\end{gathered}
$$

The change in the expected profits following the decision is the abnormal return that I am capturing in the event study. The model predicts an unambiguously positive change following a "Valid \& Infringed" decision and an unambiguously negative change following an "Invalid" decision. The change in expected profits is ambiguous following a "Not Infringed" decision (but will be positive for large values of $\alpha$ ). These outcomes are my hypotheses for the cumulative returns from the event study.

Equations (2)-(4) may also be differentiated with respect to each of the parameters to form hypotheses

\footnotetext{
${ }^{12}$ In the equations, "IN" will be used for "Invalid", " $V T$ " for "Valid \& Infringed", and "NI" for "Not Infringed".
}

about how they will affect the observed abnormal returns (which is $\Delta E(\cdot))$. The derivatives with respect to the value of the patent to the firm, $V$, are obvious and take on the same sign as the change in expectations as whole. The derivatives with respect to the probability of an "Invalid" decision, $\beta$, all take on the same value, which is positive:

$$
\frac{\delta \Delta E(\pi \mid V I)}{\delta \beta}=\frac{\delta \Delta E(\pi \mid I N)}{\delta \beta}=\frac{\delta \Delta E(\pi \mid N I)}{\delta \beta}=V
$$

These calculations form the basis for hypotheses for the cross-sectional analysis. Specifically, any factor that decreases the probability of an "Invalid" decision, $\beta$, should decrease the observed abnormal return. After the Federal Circuit was created, [2] found that invalidity rates dropped by $28 \%$. Thus, abnormal returns should be less after the Federal Circuit was created (i.e., more negative for "Invalid" decisions, less positive for "Valid \& Infringed" decisions). Characteristics of the patent that increase its value should be positively correlated with the abnormal returns for patents that were found to be "Valid \& Infringed" and negatively correlated with the abnormal returns for patents that were found to be "Invalid".

\section{The Data}

The data set used was originally presented in [2]. The data set includes all patent cases published in the United States Patent Quarterly that were decided from 19532002. The original data set included 3327 district court decisions ${ }^{13}$. Each decision was classified as either "Valid \& Infringed", "Invalid", or "Not Infringed". For patents that had inconsistent rulings for claims within a patent, we developed an hierarchal way to classify them based on previous work in the field ${ }^{14}$.

To conduct the current study, it is necessary to truncate the data set so that it begins in 1963. The Center for Research in Security Prices (CRSP) database, which provides information on daily stock prices, does not go back further than this, making an event study much more difficult for previous years. The data set was then further

\footnotetext{
${ }^{13}$ We only included the first decision by each court of a case; i.e., we didn't include district court decisions on remands, or decisions on a second appeal. Additionally, we only considered decisions that were final, excluding interlocutory rulings on motions or partial decisions. We also limited ourselves to decisions on the validity and infringement of a patent, excluding interference actions, preliminary injunction rulings, unenforceability rulings (due to fraud or inequitable conduct), contempt rulings (cases in which validity had been established in a previous case), and rulings involving collateral estoppel.

${ }^{14}$ Briefly stated, if any claim was found valid and infringed, that is the way we recorded it. If any claim was invalid and others were not infringed, the decision was recorded as "Invalid". "Not Infringed" patents included decisions that were found valid, but not infringed. Oftentimes, courts will only address either the validity question or the infringement question, but not both, making any further subclassification extremely costly in terms of lost data.
} 
reduced by excluding observations for which there was no publicly traded company listed as the patentee in the case $^{15}$. A small number of observations were also excluded because the company was a foreign entity or because the patent made no citations ${ }^{16}$. The remaining list of patent cases left me with 544 usable district court observations (from 382 litigations), of which 235 were "Invalid", 216 "Valid and Infringed", and 93 "Not Infringed." Table 1 defines the variables used and Table
2 contains some summary statistics.

As can be seen in Table 2, 23\% of the "Invalid" decisions, $44 \%$ of the "Valid \& Infringed" decisions, and $58 \%$ of the "Not Infringed" decisions occur during the CAFC-era. This breakdown is not surprising given the more frequent occurrence of the latter two types of decisions in the CAFC-era. Overall, $37 \%$ of my observations come after the establishment of the new court. The degree of "Circuit Friendliness" is consistent across all

Table 1. List of variables used.

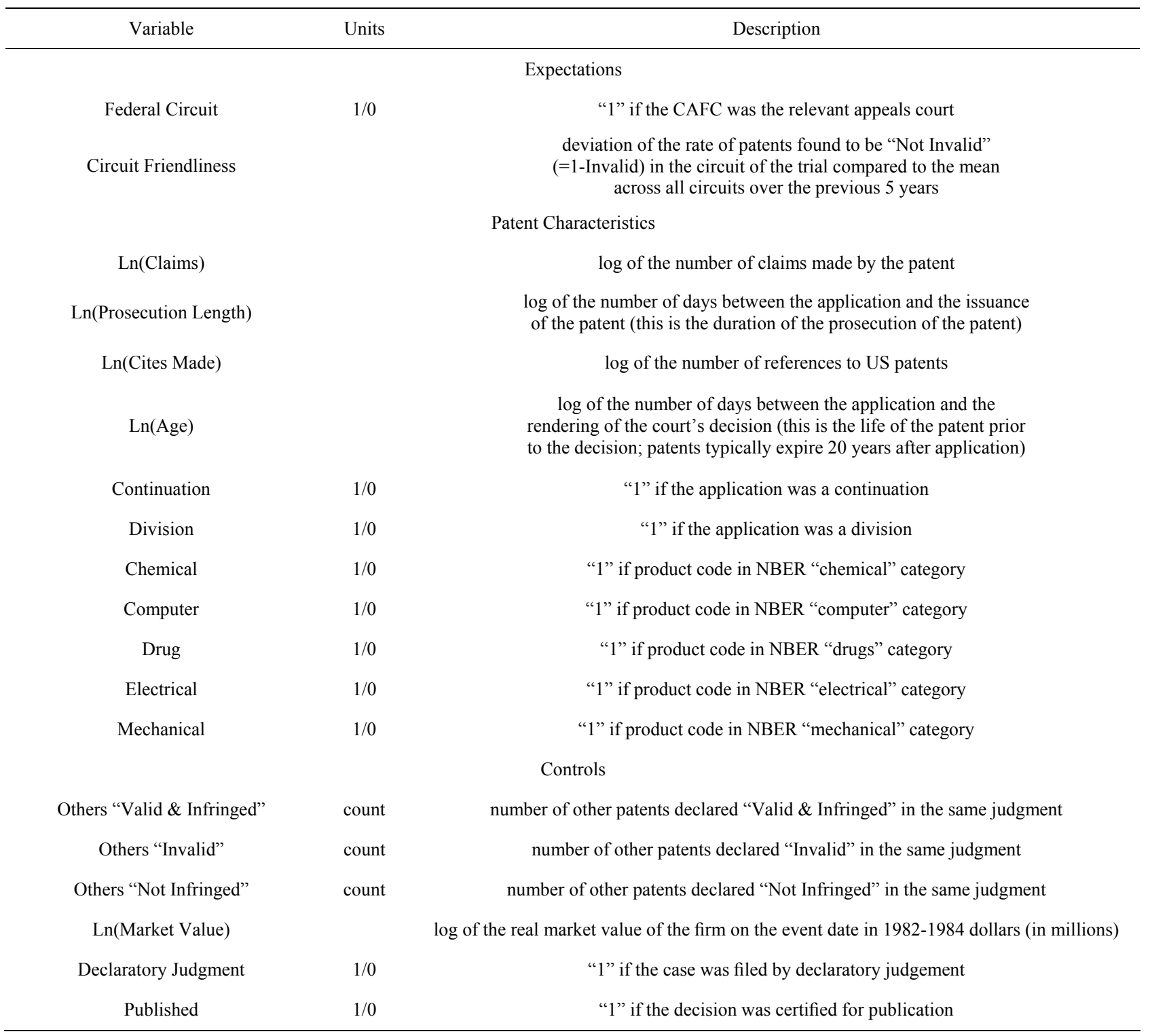

\footnotetext{
${ }^{15}$ As a robustness check, I also conducted the study focusing on the effect of the ruling on the assignee listed on the patent, who may be named as the party in interest in the suit. If the parties are different, I can't conclusively say that the first assignee is not a party in interest (or still the owner of the patent). Some of the plaintiffs may only be licensees of the patent, rather than the true owner. If that is the case, the first assignee would be the best approximation of the true owner of the patent at the time the decision was rendered, and therefore the one that we would expect to lose value if the patent is rendered invalid. In most cases, the first assignee was the same as the patent holder listed in the suit. There is no significant difference in the results.

${ }^{16}$ Since I am using logs in the cross-sectional analysis, the observations with a value of 0 had to be excluded.
} 
Table 2. Descriptive statistics.

\begin{tabular}{|c|c|c|c|c|c|c|}
\hline Decision & Invalid & $(\mathrm{N}=235)$ & Valid \& Infringed & $(\mathrm{N}=216)$ & Not Infringed & $(\mathrm{N}=93)$ \\
\hline Variable & Mean & Std. Dev. & Mean & Std. Dev. & Mean & Std. Dev. \\
\hline \multicolumn{7}{|c|}{ Expectations } \\
\hline Federal Circuit & 0.23 & $(0.42)$ & 0.44 & $(0.50)$ & 0.58 & $(0.50)$ \\
\hline Circuit Friendliness & -0.02 & $(0.14)$ & -0.01 & $(0.13)$ & -0.01 & $(0.10)$ \\
\hline \multicolumn{7}{|c|}{ Patent Characteristics } \\
\hline Claims & 11.77 & $(8.82)$ & 14.36 & (12.87) & 11.88 & $(8.42)$ \\
\hline Prosecution Length & 1023.87 & $(581.62)$ & 1119.06 & $(929.47)$ & 906.62 & $(530.33)$ \\
\hline Cites Made & 7.29 & $(5.85)$ & 9.26 & $(9.68)$ & 9.87 & $(10.17)$ \\
\hline Age & 4019.09 & $(2027.71)$ & 4432.55 & (1949.01) & 3831.29 & $(1824.02)$ \\
\hline Continuation & 0.18 & $(0.38)$ & 0.30 & $(0.46)$ & 0.25 & $(0.43)$ \\
\hline Division & 0.07 & $(0.26)$ & 0.13 & $(0.33)$ & 0.06 & $(0.25)$ \\
\hline Chemical & 0.16 & $(0.37)$ & 0.25 & $(0.44)$ & 0.11 & $(0.31)$ \\
\hline Computer & 0.04 & $(0.20)$ & 0.06 & $(0.24)$ & 0.22 & $(0.41)$ \\
\hline Drug & 0.09 & $(0.28)$ & 0.12 & $(0.33)$ & 0.13 & $(0.34)$ \\
\hline Electrical & 0.17 & $(0.38)$ & 0.10 & $(0.30)$ & 0.08 & $(0.27)$ \\
\hline Mechanical & 0.19 & $(0.39)$ & 0.17 & $(0.38)$ & 0.22 & $(0.41)$ \\
\hline Other & 0.35 & $(0.48)$ & 0.30 & $(0.46)$ & 0.25 & $(0.43)$ \\
\hline \multicolumn{7}{|c|}{ Controls } \\
\hline Others " Valid \& Infringed" & 0.20 & $(0.84)$ & 1.20 & $(1.41)$ & 0.22 & $(0.88)$ \\
\hline Others "Invalid" & 0.78 & $(1.48)$ & 0.21 & $(0.53)$ & 0.16 & $(0.50)$ \\
\hline Others "Not Infringed" & 0.06 & $(0.24)$ & 0.13 & $(0.33)$ & 1.71 & $(3.64)$ \\
\hline Real Market Value & 2260.13 & $(5213.50)$ & 2664.97 & $(5338.12)$ & 3970.47 & $(7029.83)$ \\
\hline Declaratory Judgment & 0.20 & $(0.40)$ & 0.08 & $(0.27)$ & 0.09 & $(0.28)$ \\
\hline Published & 0.50 & $(0.50)$ & 0.43 & $(0.50)$ & 0.47 & $(0.50)$ \\
\hline
\end{tabular}

three types of decision.

Patents ruled "Valid \& Infringed" tend to have more claims and longer prosecution lengths than patents ruled either "Invalid" or "Not Infringed." They also tend to be about a year older, and are more likely to have resulted from a continuation or a division of another patent application.

Typically, all the patents in a case will receive the same decision. This is seen by looking at the number of "Others Valid \& Infringed", "Others Invalid", and "Others Not Infringed" for each type of decision. The real market value of firms is much higher on average for the "Not Infringed" decisions. Although only $43 \%$ of decisions in my sample were declared "Invalid", $65 \%$ (47 out of 72) of cases that were initiated as a declaratory judgement action resulted in "Invalid" decisions. This is probably a result of the selection of weaker patents into litigation when the alleged infringer initiates the action.

\section{The Event Study Method}

An event study is the statistical method of identifying the abnormal returns to stocks due to new information in the market ${ }^{17}$. The basic regression is ${ }^{18}$ :

$$
R_{i t}=a_{i}+b_{i} R_{m t}+e_{i t}
$$

In this equation, $i$ represents a firm, $t$ represents a specific day, $R_{i t}$ is the return to the individual stock on that specific day, and $R_{m t}$ is the market return on that specific day. For my study, I use observations taken from a minimum of three and maximum of 255 days ending 46

\footnotetext{
${ }^{17}$ For a more complete description, see [11].

${ }^{18}$ This is the market model of an event study; other models can also be chosen to get the predicted values of market price.
} 
days before the event to estimate this baseline equation for each firm ${ }^{19}$. Once estimates of $a_{i}$ and $b_{i}$ are obtained, one may use those estimates and observed values of $R_{m t}$ on the event date to get a predicted value of $R_{i t}$ for each firm in the sample. The final step is to compute the difference between the predicted values of $R_{i t}$ and the actual value. This difference is the abnormal return on the event date. One may also expand the study to include days around the event date, creating an event window ${ }^{20}$.

The specification of the proper event window is important to the results of any event study. The event study framework is based on the efficient market hypothesis. This hypothesis says that a stock price will change quickly to incorporate all new publicly available information that is available to the market. Therefore, if we see a significant deviation from the predicted price within a certain event window, it is evidence that the event affected the value of the firm. If the window specified around the event is too small, there may not be enough time for the new information from the event to be incorporated into the stock price. Also, if information is leaked to the market outside of the event window, the stock price may adjust prior to entering into the window that is studied. This would lead to a false conclusion that the event had no effect on the market value of the firm. If the event window is too large, it may allow other events or new information to be included, biasing results.

In addition, the statistical power of the event study is greater for shorter windows. The statistical power of an event study increases with the number of firms in the sample because a large sample allows any errors caused by unidentifiable confounding events to decrease on average, as long as there are no systematic errors in the data. Therefore, the larger the sample size, the greater the event window that can be studied, while still allowing for meaningful results. Also, larger sample sizes and smaller event windows increase the probability of detecting small abnormal returns ${ }^{21}$.

I have a fairly large sample, which allows me to derive meaningful statistical results even for large event windows. However, it is probable that investors update their expectations about the outcome prior to final decision due to revelations during the course of the trial. The reader should keep this possibility in mind in interpreting my results.

\section{Event Study Results}

The cumulative results for each type of district court decision are presented in Table 3. I separate the observations by type of district court decision and run the event study twice. The first time, I include all the observations (denoted "All" in the table). The second set of results presented includes only the cases in which only one patent was ruled upon (denoted "Single" in the table). This second set of results is cleaner based on my model, which isn't equipped to handle disputes involving more than one patent. It is hard to predict the effect a ruling that one patent is "Valid \& Infringed" and another is "Invalid" will have on the stock market value of the firm. However, the power of the test is diminished due to the smaller sample size, especially in the longer event window.

I find that "Invalid" decisions reduce the value of a firm by nearly $1 \%$ in the three days surrounding the announcement of the decision. This translates into an average loss of about $\$ 19$ million $^{22}$. In the eleven day event window, there is an even greater drop in firm value. Both findings are statistically significant. My findings are consistent with, although larger than, [16], which found $-0.62 \%$ and $-0.84 \%$ mean abnormal returns for a

Table 3. District court mean cumulative abnormal returns.

\begin{tabular}{|c|c|c|c|c|c|c|}
\hline & Invalid & & Valid \& Infringed & & Not Infringed & \\
\hline Window & All $(\mathrm{N}=235)$ & Single $(N=126)$ & All $(\mathrm{N}=216)$ & Single $(N=83)$ & All $(\mathrm{N}=93)$ & Single $(N=45)$ \\
\hline \multirow[t]{2}{*}{$(-1,+1)$} & $-0.85 \%{ }^{* *}$ & $-0.92 \%^{*}$ & $0.73 \%^{* *}$ & $0.68 \%{ }^{*}$ & $-0.76 \%$ & $-1.13 \%$ \\
\hline & $(-3.46)$ & $(-2.28)$ & $(2.73)$ & (1.79) & $(-0.59)$ & $(-0.62)$ \\
\hline \multirow[t]{2}{*}{$(-5,+5)$} & $-1.67 \%{ }^{* *}$ & $-2.37 \%^{*}$ & $-0.23 \%$ & $0.4 \%$ & $0.24 \%$ & $0.00 \%$ \\
\hline & $(-2.77)$ & $(-2.23)$ & $(-1.26)$ & $(0.41)$ & $(0.30)$ & $(0.20)$ \\
\hline
\end{tabular}

Patell Z statistics in parentheses. ${ }^{*}$ Indicates significance at the $5 \%$ level; ${ }^{* *}$ Indicates significance at the $1 \%$ level.

\footnotetext{
${ }^{19}$ The "days" referred to in the event window are trading days, rather than calendar days. The minimum and maximum number of days used, and the period of time from which they are drawn can be specified differently. The majority of firms in my sample had information for all 255 days in this time period. As a robustness check, I also used observations beginning 46 days after the event and reached similar results. Arguments can be made as to which time period is more appropriate in the litigation context, based on trying to eliminate as much noise from the system as possible.

${ }^{20}$ Typically, the event date is denoted 0 , and an event window will be specified as (begin date, end date). For example, $(-1,1)$ denotes the three day window from the day before the event until the day after.

${ }^{21}[20]$.

${ }^{22}$ This was found by multiplying the average drop in value times the average market value. Multiplying the individual drop in value times the individual market value and then averaging results in a positive dollar figure due to some large (in both terms) outliers, and is non-sensical.
} 
two day window and an 11-day window around an "Invalid" decision. The finding of a significant negative return confirms the prediction of the model in (2).

For "Valid \& Infringed" decisions, only the results for the shorter event window turns out to be statistically significant. Both specifications show an economically significant increase in firm value (about $0.7 \%$; or $\$ 19$ million), confirming the prediction of (3). The simplest explanation for this increase is that it reflects damage awards won by the patent holder (either in the form of royalties or lost profits). Unfortunately, I don't have information on the amount of damages awarded in each case $^{23}$. However, the increase in value may also be attributable to an increase in investor's perception of the strength of a patent. Despite one valid and infringed ruling, validity may be relitigated in a subsequent suit against a different defendant ${ }^{24}$. Nonetheless, one court ruling is a strong indicator of a "good" patent, which should increase the market valuation of the patent as well. Finally, part of the increase in value is "relief" from the danger of the patent being declared "Invalid" or its scope being limited by a ruling of "Not Infringed." The drop in value for the $(-5,5)$ window is not statistically significant. The point estimates may imply that the decision to appeal is typically made quicker (i.e., within 5 days of the decision) by defendants, which would reduce value back down after a "Valid \& Infringed" decision, than by plaintiffs, which would restore some value following an "Invalid" decision.

As anticipated by (4), the "Not Infringed" decisions do not result in a statistically significant change in firm value. This result is consistent with my hypothesis that the returns following this type of decision would be ambiguous in sign. However, the drop in firm value should be less following "Not Infringed" decisions than following "Invalid" decisions, and this is not true for one of the specifications. This could simply be due to the small sample size for "Not Infringed", single case decisions.

Overall, these results are consistent with other event studies on litigation ${ }^{25}$. The overwhelming majority of previous studies find that there is no increase in value for a plaintiff upon the filing of a suit. Here, in the context of patent litigation, the explanation may be quite obvious. The drop in value from an "Invalid" decision is greater than the increase in value following a "Valid \& Infringed" decision. Thus, unless the probability of a "Valid \& Infringed" decision is greater than the probability of an "Invalid" decision, the litigation has a ne-

\footnotetext{
${ }^{23}$ Very few court decisions on damages are announced in the USPQ. It may be possible to gather this information by checking Wall Street Journal news stories or possibly information contained in the companies' financial statements.

${ }^{24}$ The same defendant would not be able to relitigate this issue after the first trial absent extraordinary circumstances, such as the revelation of new information.

${ }^{25}$ For a review of this literature, see $[11,12]$.
}

gative net expected value for the patent holder, assuming "Not Infringed" decisions have no effect on value ${ }^{26}$.

\section{Cross-Sectional Analysis}

The event study also yields the abnormal returns to each individual firm following each patent decision. These returns can then be used for cross-sectional analysis to find what variables help explain the size of abnormal returns generally. I separated the district court decisions by type and then regressed the following equation using a simple Ordinary Least Squares model, with robust standard errors:

$$
\begin{aligned}
\text { Abnormal Return }_{i} & =\alpha+\beta^{*} \text { Expectations }_{i} \\
& +\gamma^{*} \text { Characteristics }_{i} \\
& +\delta^{*} \text { Controls }_{i}+\varepsilon_{i}
\end{aligned}
$$

Under the heading "Expectations", there are two variables in the regression that should affect the expectations of investors before the decision is rendered. The first is a dummy variable that takes on a value of 1 if the Court of Appeals for the Federal Circuit was the relevant appeals court. Prior to the CAFC, it was much more likely that a patent would be declared invalid ${ }^{27}$. According to the analysis in Section 2, the abnormal returns of all three types of decisions should be positively correlated with the probability of invalidity. Since the probability of invalidity goes down if this dummy variable has a value of one, (5) predicts a negative coefficient for this variable.

The second variable in "Expectations" measures how pro-patentee the circuit in which the litigation takes place had been over the prior five years relative to all other circuits. This variable was constructed using the full data set contained in [2]. I divided the number of decisions that a patent was "Not Invalid" (=1- "Invalid") by the total number of cases decided over the previous five years for each circuit individually and then across all circuits. I then took the difference between the two values to get my new variable. Thus, as "Friendliness" goes up, the probability of invalidity goes down (relative to the same litigation taking place in a different circuit), which (5) predicts should result in a negative coefficient for all three of my dependant variables.

"Characteristics" in the regression equation above contains variables related to the patent that other researchers have found to be important determinants of patent value. These variables are: the number of claims, the

\footnotetext{
${ }^{26}$ According to [2], before the establishment of the Federal Circuit, $55 \%$ of decisions were "Invalid" and only $32 \%$ were "Valid and Infringed". After the Federal Circuit, $27 \%$ of cases were "Invalid" and $37 \%$ were "Valid \& Infringed". This later ratio will result in a slightly positive expected value, but probably not enough to cover costs of the suit.

${ }^{27}$ See Fn. 25.
} 
length of the prosecution ${ }^{28}$, the number of citations made by the patent, the age of the patent, whether the patent resulted from a continuation or a division of another patent application, and the technology category of the patent (relative to the "Other" category, which was excluded) as defined by [21]. I assume a nonlinear relationship with the first four of these variables, and therefore, use the log forms of those variables. Additionally, this allows me to interpret the coefficient estimates as elasticities. According to the analysis in Section 2 , patent value is negatively correlated with the dependent variable in the "Invalid" regression, and positively correlated with the dependent variables in the "Valid and Infringed" and "Not Infringed" regressions. With the exception of age, which will have the opposite signs, the coefficients of these variables should follow the same pattern.

Finally, "Controls" contains a list of control variables, including: the number of other patents in the same case found to be "Valid and Infringed," "Invalid," or "Not Infringed"; the log of the real market value of the firm (using 1982-1984 chain weighted dollars); whether the case arose as a declaratory judgment; and whether the deci- sion was published ${ }^{29}$.

The results of the regressions are presented in Table 4. I ran a separate regression for the subset of cases that involved only one patent because I was concerned that, even with the control variables for other patents decided at the same time, the results would nonetheless be biased. The dependant variable in each specification is the abnormal return in the $(-1,1)$ event window.

For the "Expectations" variables in the "Invalid" regressions the only statistically significant coefficient estimate is the dummy for the Federal Circuit in the single patent regression. This coefficient estimate also has the sign that the model predicts, indicating that the firm's market value dropped an additional $1.8 \%$ in the Federal Circuit era following an "Invalid" decision. Even though not statistically significant, the sign on the Federal Circuit dummy in the full regression and the sign on the measure of venue friendliness in the single patent regression are also as predicted. I believe that the full regression is biased by a large outlier created by a case in which other patents were found to be "Valid \& Infringed," and the control variables failed to fully control for this effect ${ }^{30}$. Therefore, the single patent regression is probably the more meaningful specification. In the

\footnotetext{
${ }^{28}$ The prosecution period is the time between a patent is applied for and the patent is granted by the Patent Office. Unlike [3,5], I use the application date for the patent that was granted, rather than the original application date if the patent was a continuation or a division as the beginning date of the prosecution.

${ }^{29}$ Occasionally, the United States Patent Quarterly publishes decisions that weren't certified by the judge to be published, and are not allowed to be cited as precedent in subsequent cases.
}

"Valid \& Infringed" regressions, all of the "Expectations" coefficients tested to be statistically significant and all have the predicted sign. The value rose by $1 \%-2 \%$ less in the Federal Circuit era. Additionally, a 10\% increase in "Friendliness" results in a $0.5 \%-0.7 \%$ smaller rise in the market value of the firm. None of the coefficient estimates are significant or have the predicted signs for the "Not Infringed" regressions. Rather than reflecting a flaw in the model, I think that the "Not Infringed" regressions suffer because of the insignificant results found by the event study in general. Because the change in value following such a decision is more amorphous than the other two types of decisions, it also makes it harder to "explain" the observed changes. Focusing on the three specifications that had meaningful results, "Invalid-Single" and both "Valid \& Infringed" regressions, it is apparent that the creation of the Federal Circuit made patents more valuable to firms (on the magnitude of between $1 \%-2.4 \%$ of the firm's market value). The added value comes from the reduction in the probability of the patent being declared "Invalid". After the creation of the Federal Circuit, an "Invalid" decision is more of a shock to the market, resulting in a greater drop in firm value. Additionally, if the patent is found to be "Valid \& Infringed", there is less of a relief from the possibility of the patent being declared "Invalid" relative to the same litigation before the new court was established. In other words, the increased value of the patent due to the stronger property rights are already (prior to a decision being made) incorporated into the market value of the firm. This explains why the sign of the coefficient for the dummy variable is negative in either case. The additional value of the stronger property rights is reflected in each patent-holding firm's stock price outside of the litigation context, thereby making each patent more valuable for the firm.

The same analysis is true for the "Circuit Friendliness" variable. If the patent holder is able to litigate its claims in a more friendly venue, then the patent becomes more valuable for the firm. Focusing on the same three specifications as above, a $10 \%$ increase in the friendliness of the court relative to others results in between a $0.3 \%$ $0.7 \%$ increase in the value of the patent to the firm.

As for the "Characteristics" variables, I find little evidence that confirms the work of previous researchers ([3] and [5] $)^{31}$. In the "Invalid-All" regression, the coefficient

\footnotetext{
${ }^{30}$ This case involved Amgen Inc.'s patents related to the drug Epogen, which is used to treat anemia.

${ }^{31}$ I do not test whether the number of citations received was a significant factor in determining patent value because of the lack of data available. Additionally, this variable could change at any given time, and estimating the value to solve get around the natural truncation of the variable seems problematic to me. Therefore, I can't compare my findings to [18].
} 
Table 4. District court OLS results, three day event window.

\begin{tabular}{|c|c|c|c|c|c|c|}
\hline \multirow{2}{*}{$\begin{array}{l}\text { Decision } \\
\text { Variable }\end{array}$} & \multicolumn{2}{|c|}{ Invalid } & \multicolumn{2}{|c|}{ Valid \& Infringed } & \multicolumn{2}{|c|}{ Not Infringed } \\
\hline & All & Single & All & Single & All & Single \\
\hline \multicolumn{7}{|c|}{ Expectations } \\
\hline \multirow[t]{2}{*}{ Federal Circuit } & -0.0071 & $-0.0188^{*}$ & $-0.0108 \$$ & $-0.0239^{*}$ & 0.0033 & 0.0375 \\
\hline & $(-0.91)$ & $(-2.37)$ & $(-1.68)$ & $(-2.00)$ & $(0.10)$ & $(0.54)$ \\
\hline \multirow[t]{2}{*}{ Circuit Friendliness } & 0.0294 & -0.0253 & $-0.0482^{*}$ & $-0.0747^{*}$ & 0.1587 & 0.1712 \\
\hline & $(1.12)$ & $(-0.81)$ & $(-2.41)$ & $(-2.20)$ & $(1.50)$ & $(1.18)$ \\
\hline \multicolumn{7}{|c|}{ Patent Characteristics } \\
\hline \multirow[t]{2}{*}{ Ln(Claims) } & $0.0065 \$$ & 0.0065 & 0.0005 & 0.0011 & -0.0166 & -0.0308 \\
\hline & $(1.81)$ & $(1.52)$ & $(0.16)$ & $(0.26)$ & $(-0.98)$ & $(-1.27)$ \\
\hline \multirow[t]{2}{*}{ Ln(Prosecution Length) } & -0.0001 & 0.0073 & 0.0003 & 0.0001 & -0.0350 & -0.0416 \\
\hline & $(-0.01)$ & $(0.59)$ & $(0.06)$ & $(0.02)$ & $(-1.42)$ & $(-0.74)$ \\
\hline \multirow[t]{2}{*}{ Ln(Cites Made) } & -0.0062 & -0.0074 & $0.0073^{*}$ & 0.0070 & 0.0213 & $0.0395 \$$ \\
\hline & $(-1.17)$ & $(-0.98)$ & $(2.41)$ & $(1.18)$ & $(1.36)$ & $(1.71)$ \\
\hline \multirow[t]{2}{*}{ Ln(Age) } & -0.0058 & -0.0046 & -0.0104 & -0.0003 & $0.0494 \$$ & $0.0954^{*}$ \\
\hline & $(-0.82)$ & $(-0.39)$ & $(-2.18)$ & $(-0.04)$ & (1.87) & $(2.13)$ \\
\hline \multirow[t]{2}{*}{ Continuation } & -0.0058 & -0.0056 & 0.0089 & 0.0177 & -0.0417 & -0.0465 \\
\hline & $(-0.62)$ & $(-0.35)$ & $(1.33)$ & $(1.47)$ & $(-1.27)$ & $(-1.26)$ \\
\hline \multirow[t]{2}{*}{ Division } & 0.0195 & -0.0008 & 0.0000 & 0.0312 & 0.0634 & $0.1435^{* *}$ \\
\hline & $(1.63)$ & $(-0.04)$ & $(0.00)$ & $(1.62)$ & $(1.48)$ & $(2.62)$ \\
\hline \multirow[t]{2}{*}{ Chemical } & -0.0076 & -0.0007 & -0.0020 & -0.0084 & 0.0470 & 0.0450 \\
\hline & $(-0.94)$ & $(-0.07)$ & $(-0.36)$ & $(-0.74)$ & $(1.20)$ & $(0.70)$ \\
\hline \multirow[t]{2}{*}{ Computer } & -0.0121 & -0.0100 & $-0.0367^{* *}$ & $-0.0354^{*}$ & 0.0097 & 0.0671 \\
\hline & $(-0.83)$ & $(-0.31)$ & $(-5.56)$ & $(-2.52)$ & $(0.21)$ & (1.14) \\
\hline \multirow[t]{2}{*}{ Drug } & $-0.0219 \$$ & -0.0191 & 0.0138 & 0.0175 & 0.0287 & 0.0249 \\
\hline & $(-1.70)$ & $(-1.34)$ & $(1.53)$ & $(0.94)$ & $(0.78)$ & $(0.48)$ \\
\hline \multirow[t]{2}{*}{ Electrical } & $-0.0298^{*}$ & -0.0321 & -0.0051 & -0.0387 & -0.0232 & 0.0411 \\
\hline & $(-2.54)$ & $(-1.62)$ & $(-0.52)$ & $(-1.44)$ & $(-0.57)$ & $(0.98)$ \\
\hline \multirow[t]{2}{*}{ Mechanical } & 0.0049 & -0.0086 & -0.0019 & -0.0165 & -0.0248 & -0.0096 \\
\hline & $(0.58)$ & $(-1.08)$ & $(-0.23)$ & $(-1.38)$ & $(-0.83)$ & $(-0.16)$ \\
\hline \multicolumn{7}{|c|}{ Controls } \\
\hline \multirow[t]{2}{*}{ Others "Valid \& Infringed" } & 0.0014 & - & 0.0013 & - & 0.0043 & - \\
\hline & $(0.46)$ & & $(0.60)$ & & $(0.37)$ & \\
\hline \multirow[t]{2}{*}{ Others "Invalid" } & $0.0146^{* *}$ & - & -0.0086 & - & -0.0214 & - \\
\hline & $(4.93)$ & & $(-1.20)$ & & $(-1.25)$ & \\
\hline Others "Not Infringed" & 0.0071 & - & $0.0153^{*}$ & - & -0.0012 & - \\
\hline & $(0.42)$ & & $(2.16)$ & & $(-0.31)$ & \\
\hline Ln(Market Value) & $0.0040^{*}$ & 0.0029 & 0.0005 & -0.0012 & 0.0043 & 0.0003 \\
\hline & $(2.16)$ & $(1.38)$ & $(0.40)$ & $(-0.49)$ & $(0.84)$ & $(0.03)$ \\
\hline Declaratory Judgment & 0.0111 & -0.0038 & -0.0070 & 0.0074 & -0.0899 & -0.1577 \\
\hline & $(1.56)$ & $(-0.40)$ & $(-0.86)$ & $(0.58)$ & $(-1.03)$ & $(-1.59)$ \\
\hline Published & $0.0119 \$$ & 0.0051 & $-0.0136^{* *}$ & $-0.0206^{*}$ & -0.0488 & $-0.1021^{*}$ \\
\hline & $(1.86)$ & $(0.61)$ & $(-2.69)$ & $(-2.35)$ & $(-1.55)$ & $(-2.50)$ \\
\hline$\alpha$ & 0.0017 & -0.0291 & $0.0819^{*}$ & 0.0167 & -0.1666 & -0.4863 \\
\hline & $(0.03)$ & $(-0.45)$ & $(2.25)$ & $(0.25)$ & $(-0.88)$ & $(-1.25)$ \\
\hline $\mathrm{N}$ & 235 & 126 & 216 & 83 & 93 & 45 \\
\hline$R^{2}$ & 0.3548 & 0.1737 & 0.2527 & 0.3477 & 0.2317 & 0.4691 \\
\hline
\end{tabular}

T-statistics in parentheses. \$: Indicates significance at the $10 \%$ level; ${ }^{*}$ Indicates significance at the $5 \%$ level; ${ }^{* *}$ Indicates significance at the $1 \%$ level. 
estimate of the claims variable indicates that a $10 \%$ increase in the number of claims reduces the value of the firm by $6 \%$. This variable does have the predicted sign for the "Valid \& Infringed" regressions, but has little statistical significance. The length of the prosecution is never statistically significant. The number of cites made by the patent appears to affect the value of the patent. Although the coefficient estimate is only statistically significant in the "Valid \& Infringed-All" regression, the sign is as predicted in every regression. A $10 \%$ increase in the number of cites made results in approximately a $7 \%$ increase in the value of the firm. The age of the patent (time from application to the court's decision) is also statistically significant and of the correct sign in the "Valid \& Infringed-All" regression. The coefficient implies a $10 \%$ increase in the age of the patent results in a $10 \%$ increase in the value of the firm. Whether a patent was a continuation of another patent application has the predicted sign in the first four regressions and is nearly statistically significant in the two "Valid \& Infringed" regressions. The same is true for the division variable in the "Valid \& Infringed-Single" regression. Finally, the technological category of the most valuable patents are different from the two papers cited above. They find computers and mechanical categories to be the most value, but in my regressions, those two categories rank 3 rd at best. Contrarily, I find the electrical category to be most valuable in the "Invalid" regressions, and the drugs category to be most valuable in the "Valid \& Infringed" regressions.

\section{Conclusions}

I use an event study to find the change in a firm's market value when a court rules on the validity and infringement of one or more of the firm's patents. I find that when a district court declares a patent to be "invalid" the average firm loses $0.85 \%-0.92 \%$ of its value over the three days surrounding that decision. This effect is highly economically and statistically significant. According to my model, the reduction in firm value following such a decision can be attributed to a loss in expected damages and the loss of the value of the patent. A decision that a patent is "Valid \& Infringed" only increases firm value by $0.68 \%-0.73 \%$. This gain in value can be derived from the award of damages in the case, or from relief that the patent's value to the firm may be maintained. Finally, a "Not Infringed" decision causes a statistically insignificant reduction in firm value. The lack of a predictable change in value following such a decision is the result of a loss in expected damages, counterbalanced by the relief from the chance of losing the value of patent. These results clearly show that the patent holder has more to lose in litigation than it stands to gain.

The results confirm the significant effect that the establishment of the Federal Circuit had on patent litigation. Because the Federal Circuit decreased the probability of an "Invalid" district court decision, it is more shocking when one is rendered, causing a larger decrease in firm value. Similarly, because "Valid \& Infringed" decisions are more expected, firm value increases less following such a decision. The same is true for firms that have a friendly venue within which to adjudicate their claims. When property rights become stronger, patents become more valuable to the firms that possess them. Discussing the value of patent without regard to the patent's enforceability is a significant oversight in the previous literature relating to patent value.

Investors' expectations are at least as important as the patents' characteristics in determining the change in firm value following a court's decision. These expectations, and the value derived from them, should be maintained for the firm even outside of the litigation context, meaning that the results presented here are not contingent on the particular patent ever being litigated. Rather, a universal change in the legal landscape, such as the creation of the CAFC, should raise the value of every patent, and therefore every firm that owns a patent, regardless of whether they ever litigate.

\section{REFERENCES}

[1] D. A. Burge, "Patent and Trademark Tactics and Practice," 3rd Edition, John Wiley \& Sons, Inc., Hoboken, 1999. doi:10.1002/9780470172285

[2] M. D. Henry and J. L. Turner, "The Court of Appeals for the Federal Circuits Impact on Litigation," Journal of Legal Studies, Vol. 35, No. 1, 2006, pp. 85-118. doi:10.1086/498834

[3] J. R. Allison, M. A. Lemley, K. A. Moore and R. D. Trunkey, "Valuable Patents," Georgetown Law Journal, Vol. 92, No. 3, 2004, pp. 435-479.

[4] J. O. Lanjouw and M. Schankerman, "Characteristics of Patent Litigation: A Window on Competition," RAND Journal of Economics, Vol. 32, No. 1, 2001, pp. 129-151. doi: $10.2307 / 2696401$

[5] K. A. Moore, "Worthless Patents," Berkeley Technology Law Journal, Vol. 20, No. 4, 2005, pp. 1521-1552.

[6] B. H. Hall, A. Jaffe and M. Trajtenberg, "Market Value and Patent Citations," RAND Journal of Economics, Vol. 36, No. 1, 2005, pp. 16-38.

[7] K. Engelmann and B. Cornell, "Measuring the Cost of Corporate Litigation: Five Case Studies," Journal of Legal Studies, Vol. 17, No. 2, 1988, pp. 377-399. doi:10.1086/468134

[8] S. Bhagat, J. A. Brickley and J. L. Coles, "The Wealth Effects of Interfirm Lawsuits," Journal of Financial Economics, Vol. 35, No. 2, 1994, pp. 221-247. doi:10.1016/0304-405X(94)90005-1

[9] S. Bhagat, J. Bizjak and J. L. Coles, "The Shareholder Wealth Implications of Corporate Lawsuits," Financial 
Management, Vol. 27, No. 4, 1998, pp. 5-27. doi: $10.2307 / 3666410$

[10] J. Bessen and M. J. Meurer, "The Private Costs of Patent Litigation," Boston University School of Law Working Paper 07-08, 2007.

[11] S. Bhagat and R. Romano, "Event Studies and the Law: Part I: Technique and Corporate Litigation," American Law and Economics Review, Vol. 4, No. 1, 2002, pp. 141168. doi:10.1093/aler/4.1.141

[12] S. Bhagat and R. Romano, "Event Studies and the Law: Part II: Empirical Studies of Corporate Law," American Law and Economics Review, Vol. 4, No. 2, 2002, pp. 380423.

[13] J. M. Bizjak and J. L. Coles, "The Effect of Private Antitrust Litigation on the Stock-Market Valuation of the Firm," American Economic Review, Vol. 85, No. 3, 1995, pp. 436-461.

[14] D. H. Austin, “An Event-Study Approach to Measuring Innovative Output: The Case of Biotechnology," American Economic Review, Vol. 83, No. 2, 1993, pp. 253-258.

[15] A. C. Marco, "The Value of Certainty in Intellectual Property Rights: Stock Market Reactions to Patent Litiga- tion," Working Paper, 2005.

[16] A. C. Marco, "Learning by Suing: Structural Estimates of Court Errors in Patent Litigation," Vasser College Economics Working Paper 68, 2005.

[17] S. Kortum and J. Lerner, "Stronger Protection or Technological Revolution: What Is behind the Recent Surge in Patenting?" Carnegie-Rochester Series on Public Policy, Vol. 48, 1998, pp. 247-304. doi:10.1016/S0167-2231(98)00023-2

[18] B. H. Hall, "Exploring the Patent Explosion," Journal of Technology Transfer, Vol. 30, No. 1-2, 2005, pp. 35-48. doi:10.1007/s10961-004-4356-9

[19] J. Lerner, "Patenting in the Shadow of Competitors," Journal of Law and Economics, Vol. 38, No. 2, 1995, pp. 463-495. doi:10.1086/467339

[20] C. MacKinlay, "Event Studies in Economics and Finance," Journal of Economic Literature, Vol. 35, No. 1, 1997 , pp. 13-39.

[21] B. H. Hall, A. Jaffe and M. Trajtenberg, "The NBER Patent Citations Data File: Lessons, Insights and Methodological Tools,” NBER Working Paper 8498, 2001. 